Splenic metastasis from malignant melanoma is an extremely rare occurrence and is most often reported during autopsy. As in other solid tumors, splenic metastasis is usually part of multiple organ metastases in melanoma and is rarely an isolated or solitary mass. As the use of positron emission tomography /computed tomography and imaging techniques become more common, splenic metastases are seen more often than before. Even though it is a commonly known fact that positron emission tomography/computed tomography is no help during primary staging and patient relations in malignant melanoma, several studies and meta-analyses have proven that it is more specific, sensitive and accurate to identify metastases than raditional methods. Therefore, using techniques with high specificity and accuracy rates such as positron emission tomography/computed tomography in the diagnosis of splenic metastasis in patients with malignant melanoma will increase the survival rate with an earlier splenectomy. We report the case of a 35-year-old male patient with cutaneous malignant melanoma whose splenic metastasis was detected with positron emission tomography/computed tomography. This article describes, with reference to the literature, a malignant melanoma case, which presented with splenomegaly and solitary mass lesion and was diagnosed as metastasis by splenectomy after positron emission tomography/computed tomography.

Key words: isolated splenic metastasis, malignant melanoma, splenectomy, $\mathrm{PET} / \mathrm{CT}$.

\section{Isolated and solitary splenic metastasis detected by positron emission tomography in a patient with malignant melanoma: case report and review of the literature}

\author{
Cenk Ahmet Sen ${ }^{1}$, Aysegul Kargi ${ }^{2}$, Vildan Kaya ${ }^{3}$, Ozgur Tanriverdi ${ }^{4}$
}

1Denizli State Hospital, Department of Radiation Oncology, Denizli, Turkey 2Denizli State Hospital, Department of Medical Oncology, Denizli, Turkey

3Süleyman Demirel University Faculty of Medicine, Department of Radiation Oncology, Isparta, Turkey

${ }^{4}$ Mugla University Training and Research Hospital, Department of Medical Oncology, Mugla, Turkey

\section{Introduction}

Splenic metastasis is a very rare occurrence in solid tumors, especially melanoma, and is usually a co-morbidity to multiple organ involvement. Isolated splenic metastasis, however, is rarely observed [1, 2]. For a solitary mass which is isolated in the spleen and does not meet the features of radiological and functional imaging malignancy, invasive procedures are the secondary option in addition to constant follow-up. In such cases, it is very hard to decide to perform diagnostic techniques such as biopsy and splenectomy [1-3].

As imaging techniques are more frequently used and positron emission tomography/computed tomography (PET/CT) hybridization has increased the sensitivity, specificity and accuracy rates for diagnosis of malignant diseases, in comparison with traditional methods, splenic metastases are reported more often $[3,4]$. Even though it is a commonly known fact that PET/CT is no help during primary staging and patient relations in malignant melanoma, several studies and meta-analyses have proven that it is more specific, sensitive and accurate to identify metastases than traditional methods [6, 7].

Our objective in this article is to present a patient with malignant melanoma and isolated and solitary splenic metastasis imaged by PET/CT by means of information available in the literature.

\section{Case report}

A 35-year-old male patient who presented with the complaint of swelling under his left arm was diagnosed with left axillary mass excision and malignant melanoma in 2008. Pathologically it was grossly $1.5 \mathrm{~cm}$, microscopically Breslow $11 \mathrm{~mm}$, Clark's level IV (T4), number of mitoses 1.2 per $\mathrm{mm}^{2}$, without ulcerations, and all margins were negative. During imaging examinations, no distant metastasis was identified, nor was it assessed as stage 3 according to the American Joint Committee on Cancer 2002 staging system. The patient was treated with adjuvant high-dose interferon therapy. A $20 \times 18 \mathrm{~mm}$ lesion in the lower spleen pole and splenomegaly was detected in the computed tomography (CT) after the treatment was completed and since there was no distinct contrast involvement, it was assessed as benign. Even though there was no significant growth in lesion size according to the imaging examinations that were performed every six months, because of the rise in activity values in F-18-fluorodeoxy-D-glucose PET/CT (Figs. 1, 2 and 3) a splenectomy 


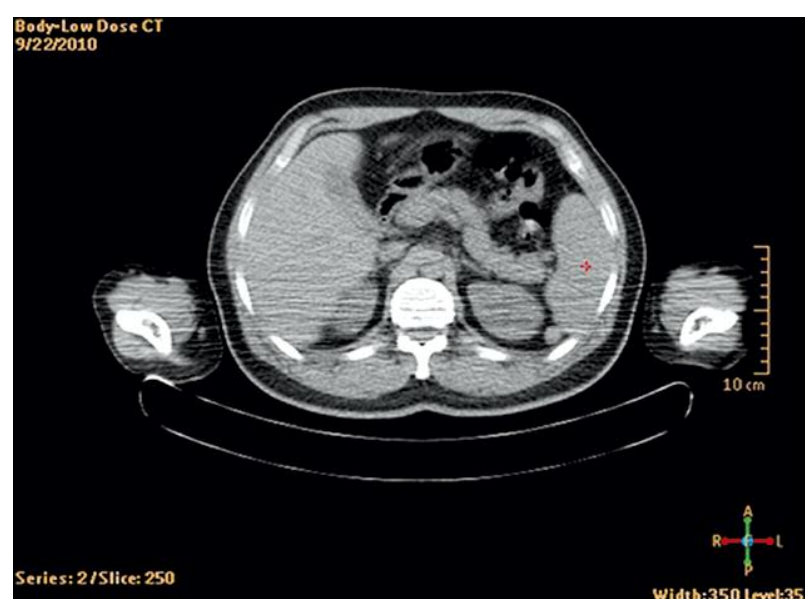

Fig. 1. Anatomic imaging with PET/CT; heterogeneous lesion in lower spleen pole

was performed on the patient, in October 2011. As the splenectomy material was examined, it was assessed as melanoma metastasis (Fig. 4). The patient was started on treatment with temozolamide and is still being followed after the third year since the diagnosis at our department.

\section{Discussion}

Even though the spleen is a more vascularized organ, metastasis of solid tumors is a very rare observation. This

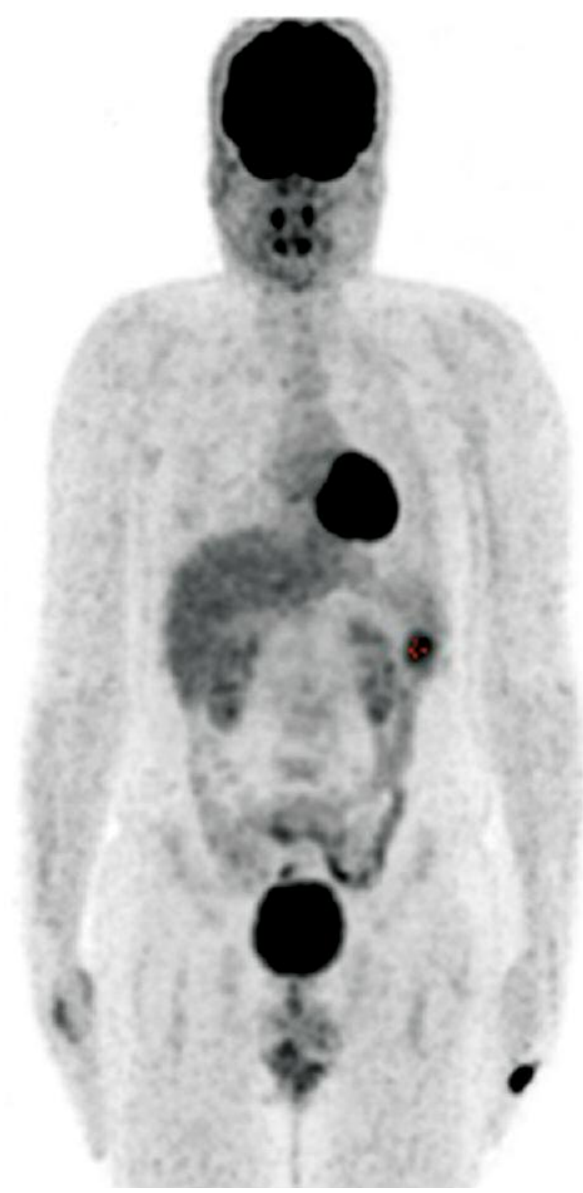

Fig. 3. 3D splenic imaging with $\mathrm{PET} / \mathrm{CT}$; isolated hyperactive involvement in splenic area

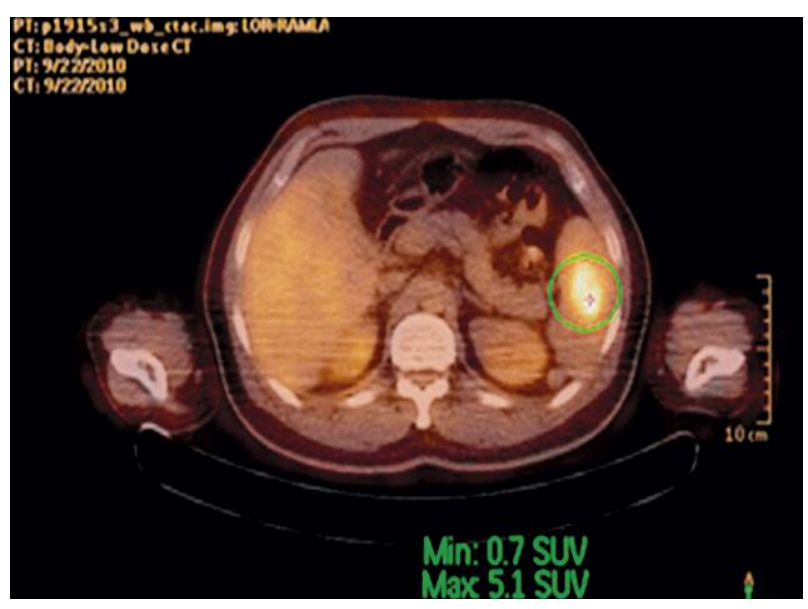

Fig. 2. Fusion imaging with $\mathrm{PET} / \mathrm{CT}$; hyperactive lesion in spleen

situation is explained by spleen parenchyma's natural ability to resist metastases. Forming a physical barrier by the splenic capsule, the immunological defense ability of the spleen against neoplastic cells, and angular and gyroid structure of the splenic artery are some of the explanations given for this resistance [8]. Before 1990, when imaging techniques were not used effectively, splenic metastasis rates were between $2.3 \%$ and $7.1 \%$ and most of them were found during autopsies or were just encountered coincidentally [9]. In one of these studies, in an autopsy study that Berg et al. performed in 1974, they reported that $4.3 \%$ of 7165 cases $(n=312)$ had splenic metastases. Again in this study, splenic metastases were observed in cases that had at least five visceral organs [10].

In the studies that were performed after 1990 when imaging techniques and life expectancy of patients had started to improve, the number of reports on multiple organ metastases or the number of cases with solitary spleen metastasis increased. In a study performed by Kraus et al., splenic

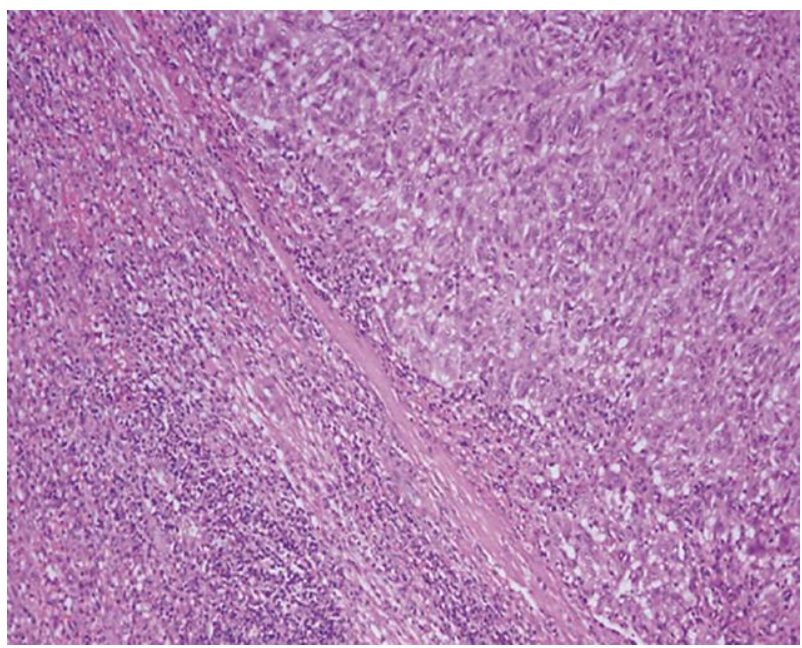

Fig. 4. Malignant melanoma metastasis to the spleen; histopathological examination by splenectomy; the characteristics of the tumor were observed to be oval-round cells creating solid islands and nest with mostly eosinophilic and pleomorphic nuclei (HE, magnification 20x). Additional immunohistochemical dyes were applied for this diagnosis 
metastasis was observed in $1.3 \%$ of 1280 cases that underwent a splenectomy, and in a Japanese study, $0.15 \%$ of 24761 patients who underwent an ultrasonographic examination [11, 12]. The most important clinical result of these cases was the early diagnose of masses on kidneys using effective imaging techniques.

Among autopsy studies and clinical case series, the most common cancer types (except for lymphoma) that cause splenic metastasis are breast (22.9\%), lung (20.2\%), colorectal (9.4\%), ovary (9\%) and stomach (6.9\%). Splenic metastases of other solid tumors are seen rarely and one of these is malignant melanoma. For malignant melanoma, the rate of multiple organ involvement with a co-morbid splenic metastasis is $5 \%$ but solitary splenic metastasis is reported to be $2 \%$. There are some cases of splenic metastasis development with spontaneous splenic ruptures but the clinical course is followed only in splenomegaly [13-15]. Splenic metastasis is mostly seen as part of multiple organ metastases and, in some rare occasions, as solitary metastases. In a study of Compérat et al., only 2 of 94 patients with solitary splenic metastasis had malignant melanoma. When diagnosing solitary metastasis, splenectomy and invasive methods, tru-cut and fine needle biopsies were preferred [16]. PET/CT, being more specific and sensitive than traditional methods, was reported to have shortened the period leading to splenectomy, as in our case.

Most splenic metastases are asymptomatic. As the use of efficient imaging techniques, especially PET/CT, has become more common, asymptomatic splenic metastasis cases have been reported more often [2, 3]. Splenic metastasis may present with such symptoms as asthenia, weight loss, fever, stomach ache, splenomegaly, anemia caused by hypersplenism and/or thrombocytopenia and splenic rupture in rare instances $[14,15]$. In our case, there were no clinical outcomes except for splenomegaly and mass lesion growth that could not be followed by conventional imaging techniques.

Distant metastasis development in a patient with malignant melanoma is a sign of poor prognosis and according to the American Joint Committee on Cancer staging system, for patients in stage IV, the average life period remaining is 4-8 months [17]. For patients with metastatic disease, suggested treatments are chemotherapy, radiotherapy or both. However, survival rates and patient response rates for these treatment modalities are quite low [17-19]. There are case reports and series about patients with stage 4 malignant melanoma that report long life expectancy after surgery. Especially with metastasectomies for isolated lung metastasis, gastrointestinal metastasis and metastases of other visceral organs, rates of 5 -year survival have increased to $20-40 \%$. But these rates reflect the results of certain specific patient groups. There is only one significant study in the literature about the effects of splenectomy on splenic metastases, consisting of 15 case series; this study reports survival time of 20 months. In this case series, there are 2 intriguing cases with survival times of 29 and 30 months [20-22].

In Conclusion, isolated and solitary splenic masses play an important role in diagnostic and treatment phases of malignant melanoma, as in all other solid tumors. Especially in cases such as malignant melanoma that is curable through surgical resection, traditional imaging techniques and false negative values hinder the period of diagnosis and splenectomy. Although there is no certainty of the effects of splenectomy on survival rate in malignant melanoma cases with isolated splenic metastasis, it can be assumed to have similar success as metastasectomy performed in other areas of metastasis. Therefore, using techniques with high specificity and accuracy rates such as PET/CT in the diagnosis of splenic metastasis in patients with malignant melanoma will increase the survival rate with an earlier splenectomy.

The authors declare no conflict of interest.

\section{References}

1. Görg C, Hoffmann A. Metastases to the spleen in 59 cancer patients: a 14-year clinicosonographic study. Ultraschall Med 2008; 29: 173-8.

2. Schön CA, Görg C, Ramaswamy A, Barth PJ. Splenic metastases in a large unselected autopsy series. Pathol Res Pract 2006; 202: 351-6.

3. Imada H, Nakata H, Horie A. Radiological diagnosis of splenic metastasis and its prevalence at autopsy. Nihon Igaku Hoshasen Gakkai Zasshi 1991; 51: 498-503.

4. Quarles van Ufford HM, Zoon PJ, van Waes PF, van Herk G, de Klerk JM. Solitary splenic metastasis in a patient with a malignant melanoma diagnosed with F-18-FDG PET scanning. Clin Nucl Med 2005; 30: 582-3.

5. Wagner JD, Schauwecker D, Davidson D, et al. Inefficacy of F-18 fluorodeoxy D-glucose-positron emission tomography scans for initial evaluation in early-stage cutaneous melanoma. Cancer 2005; 104: 570-9.

6. Friedman KP, Wahl RL. Clinical use of positron emission tomography in the management of cutaneous melanoma. Semin Nucl Med 2004; 34: 242-53.

7. Belhocine TZ, Scott AM, Even-Sapir E, Urbain JL, Essner R. Role of nuclear medicine in the management of cutaneous malignant melanoma. J Nucl Med 2006; 47: 957-67.

8. Lee SS, Morgenstern L, Phillips EH, Hiatt JR, Margulies DR. Splenectomy for splenic metastases: a changing clinical spectrum. Am Surg 2000; 66: 837-40.

9. Lam KY, Tang V. Metastatic tumors to the spleen. Arch Pathol Lab Med 2000; 124: 526-30.

10. Berge T. Splenic metastasis, frequencies, and patterns. Acta Pathol Microbiol Scand 1974; 82: 499-506.

11. Kraus MD, Fleming MD, Vonderheide RH. The spleen as a diagnostic specimen: a review of 10 years' experience at two tertiary care institutions. Cancer 2001; 91: 2001-9.

12. Ishida H, Konno K, Ishida J, Shirayama K, Naganuma H, Komatsuda T, Hamashima Y, Masamune O. Isolated splenic metastases. J Ultrasound Med 1997; 16: 743- 9 .

13. Buzbee TM, Legha SS. Spontaneous rupture of spleen in a patient with splenic metastasis of melanoma. A case report. Tumori 1992; 78: 47-8.

14. Krapohl BD, Kömürcü F, Deutinger M. Spleen rupture due to metastasis of thin melanoma (Breslow thickness of $0.75 \mathrm{~mm}$ ). Melanoma Res 2005; 15: 135.

15. Klein B, Stein M, Kuten A, Steiner M, Barshalom D, Robinson E, Gal D. Splenomegaly and solitary spleen metastasis in solid tumors. Cancer 1987; 60: 100-2.

16. Compérat E, Dupas AB, Camparo P, Capron F, Charlotte F. Splenic metastases: clinicopathologic presentation, differential diagnosis, and pathogenesis. Arch Pathol Lab Med 2007; 131: 965-9.

17. Trindade MM, Blaya R, Trindade EN. Melanoma metastasis to the spleen: laparoscopic approach. J Min Access Surg 2009; 5: 17-9. 
18. Toorop R, van Schil P, Hendriks J, van den Brande F, De Maeseneer M. Pulmonary metastasectomy in a patient with malignant melanoma after a disease-free interval of 15 years. Int Surg 2000; 85: 116-7.

19. Lewis CW Jr, Harpole D. Pulmonary metastatsectomy for metastatic malignant melanoma. Semin Thorac Cardiovasc Surg 2002; 14: 45-8.

20. Schuhan C, Muley T, Dienemann H, Pfannschmidt J. Survival after pulmonary metastatsectomy in patients with malignant melanoma. Thorac Cardiovasc Surg 2011; 59: 158-62.

21. Chua TC, Saxena A, Morris DL Surgical metastasectomy in AJCC Stage IV M1c melanoma patients with gastrointestinal and liver metastases. Ann Acad Med Singapore 2010; 39: 634-9.

22. Stoeter D, Carino NL, Marshall E, Poston GJ, Wu A. Extensive necrosis of visceral melanoma metastases after immunotherapy. World J Surg Oncol 2008; 6: 30-6.

\section{Address for correspondence}

\section{Dr. Ozgur Tanriverdi}

Mugla Universitesi Egitim ve Arastirma Hastanesi

Onkoloji Poliklinigi

48000 Mugla, Turkey

tel. +90252 2141326

fax +90252 2126804

e-mail: ozgurtanriverdi@hotmail.com

Submitted: 11.12.2011

Accepted: 23.07.2012 